\title{
THE PROTHROMBIN FACTOR II G20210A MUTATION WITH PULMONARY THROMBOEMBOLISM AND A NORMAL LEVEL OF FIBRIN DEGRADATION PRODUCTS
}

\author{
Nagorni-Obradovic $\mathrm{Lj}^{1,2}$, Miljic $\mathrm{P}^{1,3}$, Djordjevic $\mathrm{V}^{4}$, Pešut $\mathrm{DP}^{1,2 *}$, \\ Jovanovic $\mathrm{D}^{1,2}$, Stojsic J ${ }^{2}$, Stevic $\mathrm{R}^{2}$, Radojkovic $\mathrm{D}^{4}$
}

\begin{abstract}
*Corresponding Author: Dragica P. Pešut, School of Medicine University of Belgrade, Clinical Centre of Serbia, Institute of Lung Disease and Tuberculosis, Research and Epidemiology Department, Visegradska 26/20, 11000 Belgrade, Serbia; Tel.: +381-11-3615561; Fax: +381-112681591; E-mail: dragica.pesut@gmail.com
\end{abstract}

\begin{abstract}
Diagnosis of pulmonary thromboembolism (PTE) usually includes clinical pretest probability assessment, testing for specific degradation products of cross-linked fibrin (D-dimer) and imaging studies. Patients with radiological findings attributable to pulmonary infarction and normal D-dimer level, may present a diagnostic and therapeutic challenge. A 37-year-old Caucasian female had episodes of hemoptysis, and bilateral pulmonary nodular infiltrates on chest radiograph and computerized tomography. The plasma D-dimer level was normal, perfusion lung scan was not conclusive and histological examination of an open lung biopsy revealed recent thrombotic pulmonary infarction. She deteriorated and more perfusion defects were detected on perfusion lung scan. Genetic analysis revealed her to be a carrier of the prothrombin factor II (FII) G20210A mutation.
\end{abstract}

1 Department of Internal Medicine, School of Medicine, University of Belgrade, Belgrade, Serbia

2 Institute of Lung Diseases and Tuberculosis, Clinical Centre of Serbia, Belgrade, Serbia

3 Institute of Hematology, Clinical Centre of Serbia, Belgrade, Serbia

4 Institute of Molecular Genetics and Genetic Engineering, Belgrade, Serbia
Key words: Surgical procedure, Thromboembolism, Cross-linked fibrin (D-dimer), Factor II (FII) G20210A mutation, Risk factor

\section{INTRODUCTION}

Pulmonary infarction usually results from pulmonary thromboembolism (PTE), and typically appears on radiological examination as a peripheral wedge-shaped density above the diaphragm $[1,2]$. Nodular opacities are rare and may not be distinguished from nodular infiltrates produced by malignant disorders, granulomatous disorders or infections [3]. It is generally accepted that normal plasma level of D-dimer (specific degradation products of cross-linked fibrin) excludes PTE, and argues in favor of an alternative diagnosis [4]. Surgical lung biopsy and histological examination may be required in order to establish the nature of nodular opacities [3]. In theory, surgical intervention in a patient with recent pulmonary infarction may increase the risk of additional thrombotic events, however, the occurrence of thromboembolic complications following surgical lung biopsy has not been reported. Appropriate perioperative antithrombotic prophylaxis in patients undergoing surgical biopsy, especially when blood hypercoagulability is also present, is essential to prevent thrombotic events.

We here report on a patient with atypical pre- 
sentation of pulmonary infarction, who developed pulmonary embolism soon after open lung biopsy. Hematological investigation revealed the presence of thrombophilia which was then shown to be due to heterozygous FII G20210A mutation [5].

\section{CASE REPORT}

A 37-year-old Caucasian female, ex-smoker, was admitted for persistent mild chest pain following hemoptysis which occurred 3 weeks previously. She had been receiving angiotensin converting enzyme (ACE) inhibitor therapy for systemic hypertension for 5 years. She was not obese and had never used oral contraceptives. There was no family history of thrombosis and investigation for family thrombophilia was not performed.

She was afebrile, with a heart rate of 100 beats $\mathrm{min}^{-1}$, blood pressure $130 / 80 \mathrm{mmHg}$, and respira- tory rate 18 breaths $\mathrm{min}^{-1}$. An electrocardiogram, routine laboratory findings and arterial blood-gas analysis gave normal results. Blood sedimentation rate and leukocyte count were increased $\left(80 \mathrm{~mm} \mathrm{~h}^{-1}\right.$ and $12.6 \times 10^{9} / \mathrm{L}$, respectively).

Chest X-ray examination and computerized tomography (CT) (Figure 1, Figures 2a and 2b) showed bilateral nodular infiltrates in the lower lung lobes. The D-dimer level, measured several times by an immunoturbidometric method (DadeBehring, Deerfield, IL, USA), was $<250 \mu \mathrm{g} \mathrm{L}^{-1}$ (normal $<250$ ). Perfusion lung scans showed a subsegmental perfusion defect in the laterobasal part of the right lung, and a postero-basal hypoperfusion zone in the left lung. The ventilation scan was not available, and the perfusion scan was interpreted as non diagnostic. Antinuclear antibodies (ANA), antineutrophil cytoplasmic antibodies (ANCA) and antiphospholipid antibodies were not present. The

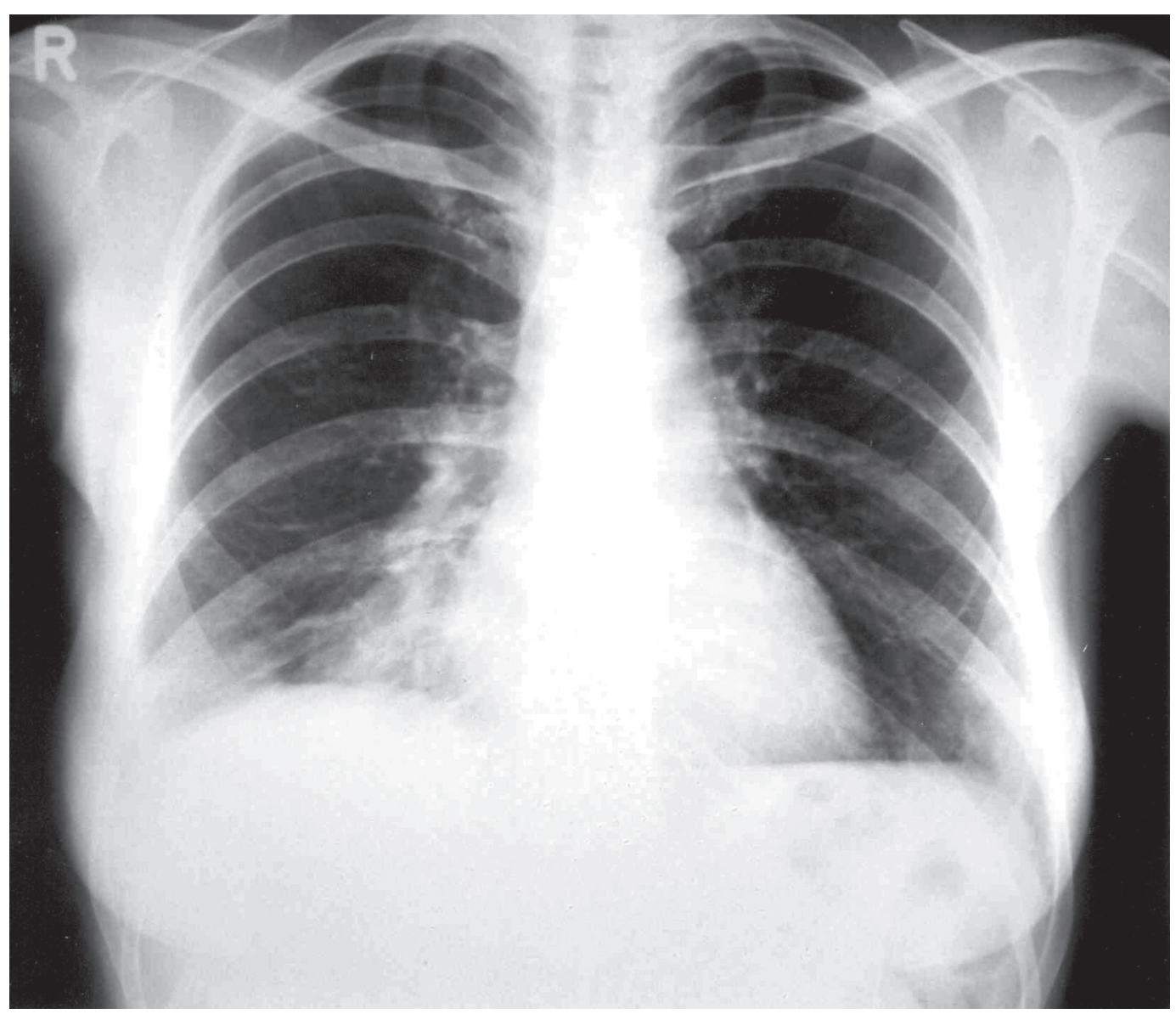

Figure 1. Standard postero-anterior chest radiograph of patient on admission. The radiograph shows bilateral irregular shadows in lower pulmonary lobes. 
$2 \mathrm{a}$

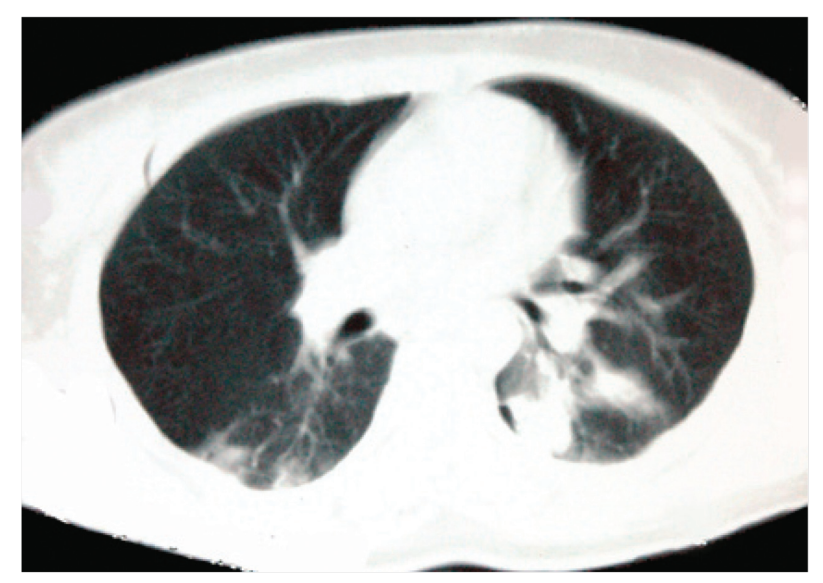

$2 b$

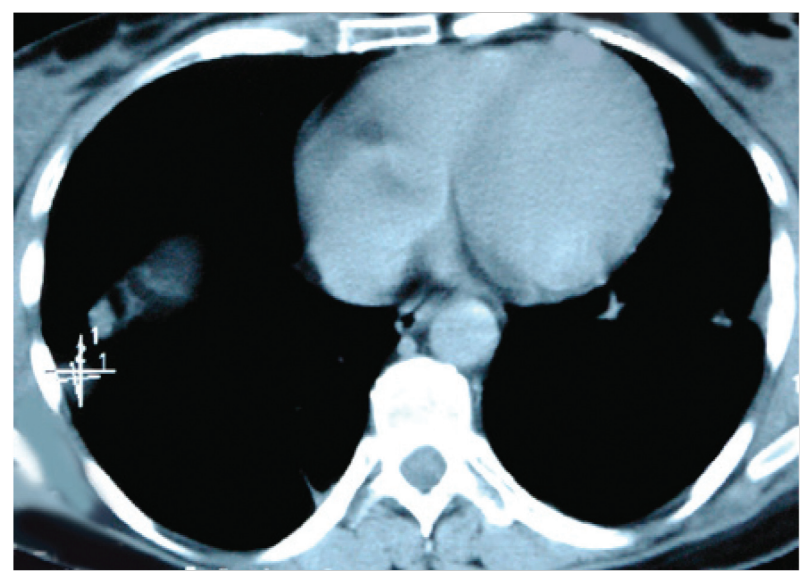

Figures 2a and $\mathbf{2 b}$. Transverse CT scan at lung window level shows bilateral irregular shadows, similarly shaped and close to each other and to pleura in posterior lower lobes, bilaterally.

sputum smear was negative for Mycobacteria.

Bronchoscopy showed some old blood in the trachea, starting from bronchus number eight of the right lower pulmonary lobe, from where an aspirate was taken for cytological and bacterial analyses. After this aspiration, bronchial hyperemia was evident but there were no signs of infiltration. The aspirate was negative for malignant cells and pathologic bacterial flora.

To clarify the nature of the bilateral nodular lung infiltrates, open lung biopsy was performed, without perioperative antithrombotic prophylaxis. A macroscopically, well bordered, ovoid hemorrhagic nodule was removed. On histological examination, recent hemorrhagic pulmonary infarction with subocclusive and occlusive thrombosis of pulmonary arterioles was noted (Figures $3 a$ and $3 b$ ). Two days after the lung biopsy, she had sharp chest pain and a chest radiograph revealed a triangular shadow in the right middle lung field (Figure 4). Arterial blood gas analysis showed $\mathrm{PaO}_{2}: 9.1 \mathrm{kPa}$ (standard value $11.45 \mathrm{kPa}$ ), and a D-dimer level of $1820 \mu \mathrm{g} \mathrm{L}^{-1}$. The perfusion lung scan showed a massive defect in the middle and lower parts of the right and segmental defects in basal part of the left lung. Compression ultrasonography of lower limb veins gave negative results for the presence of deep venous thrombosis (DVT). Hematological investigation revealed presence of a thrombophilic state. Genetic analysis showed a heterozygous FII G20210A mutation (see Methodology Description below). Activities of protein $\mathrm{C}$, protein $\mathrm{S}$ and antithrombin III were normal. The polymerase chain reaction (PCR), analysis for factor $\mathrm{V}$ Leiden mutation was negative, and anticardiolipin antibodies were not elevated.

Intravenous heparin was introduced, followed by warfarin, keeping the international rate (INR) of prothrombin time at 2-3. The patient's clinical state gradually improved, and over 2 years of follow-up she had no new thrombotic episodes.

Methodology Description. The fragment of the factor II gene was amplified by PCR on whole blood, followed by digestion with HindIII (New England BioLabs, Ipswich, MA, USA) endonuclease. The digestion products were analyzed by electrophoresis on $10 \%$ polyacrylamide gels followed by silver staining of the gels. We used the following modification of the PCR according to Poort et al. [5]: PCR reactions were performed in a $25 \mu \mathrm{L}$ final volume containing $50 \mathrm{mM} \mathrm{KCl}, 100$ $\mathrm{mM}$ Tris- $\mathrm{HCl}, \mathrm{pH} 9.0,0.1 \%$ Triton $\mathrm{X}-100,200 \mathrm{mM}$ dNTPs, $5 \mathrm{mM} \mathrm{MgCl} 2,10 \mathrm{pmol}$ of forward and reverse primers and $1 \mu \mathrm{L}$ of whole blood. The thermal cycle profile was: five cycles consisting of 3 min. at $98^{\circ} \mathrm{C}$ and $3 \mathrm{~min}$. at $55^{\circ} \mathrm{C}$, to assure complete denaturation of DNA. One unit Taq polymerase (Applied Biosystems, Foster City, CA, USA) was added at $50^{\circ} \mathrm{C}$ and after 5 min., 35 cycles consisting of denaturation at $94^{\circ} \mathrm{C}$ for $1 \mathrm{~min}$., annealing at $56^{\circ} \mathrm{C}$ for $1 \mathrm{~min}$. and polymerization at $72^{\circ} \mathrm{C}$ for $1 \mathrm{~min}$. were applied. Final extension of the PCR 
$3 \mathrm{a}$

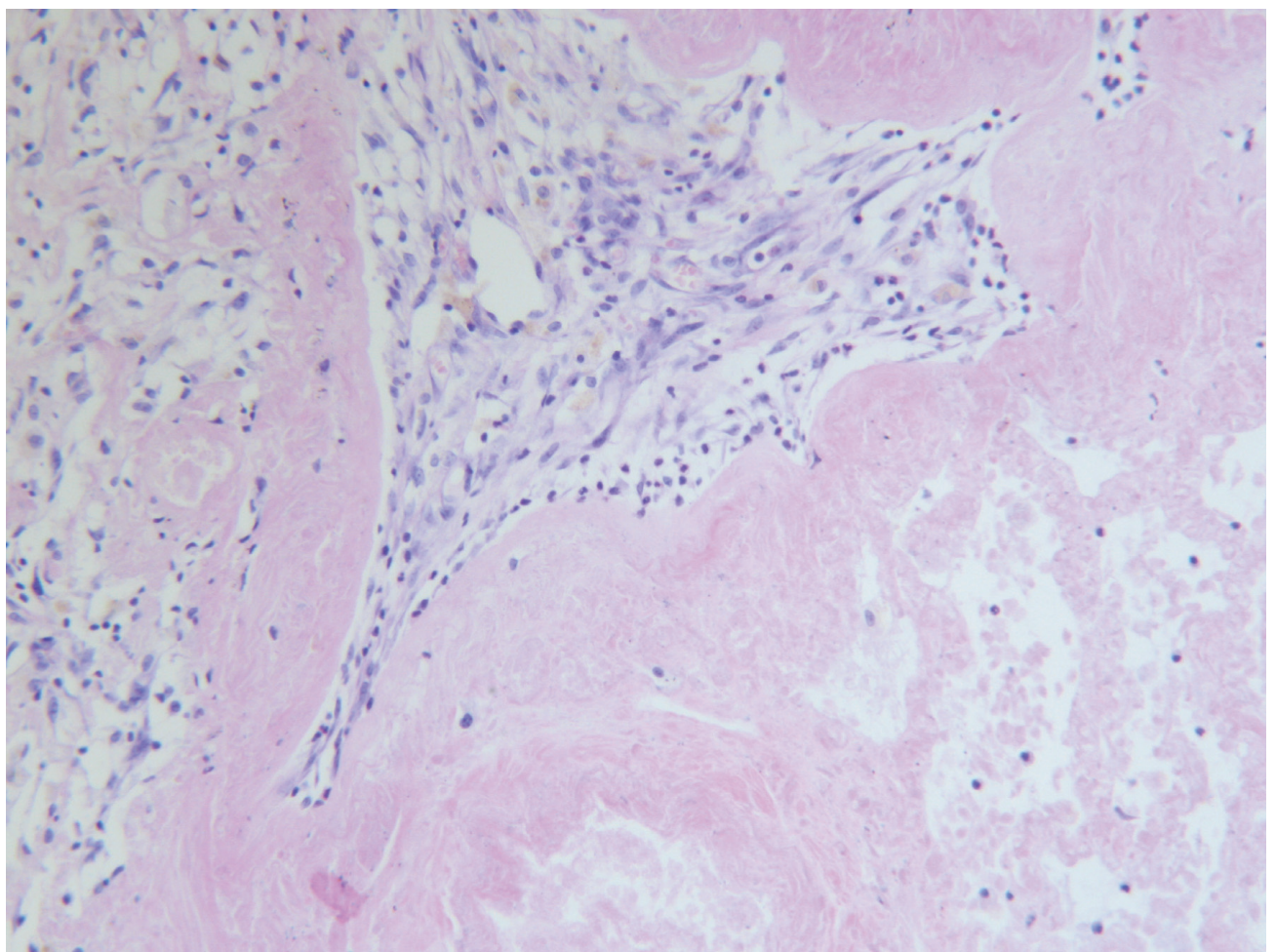

$3 b$

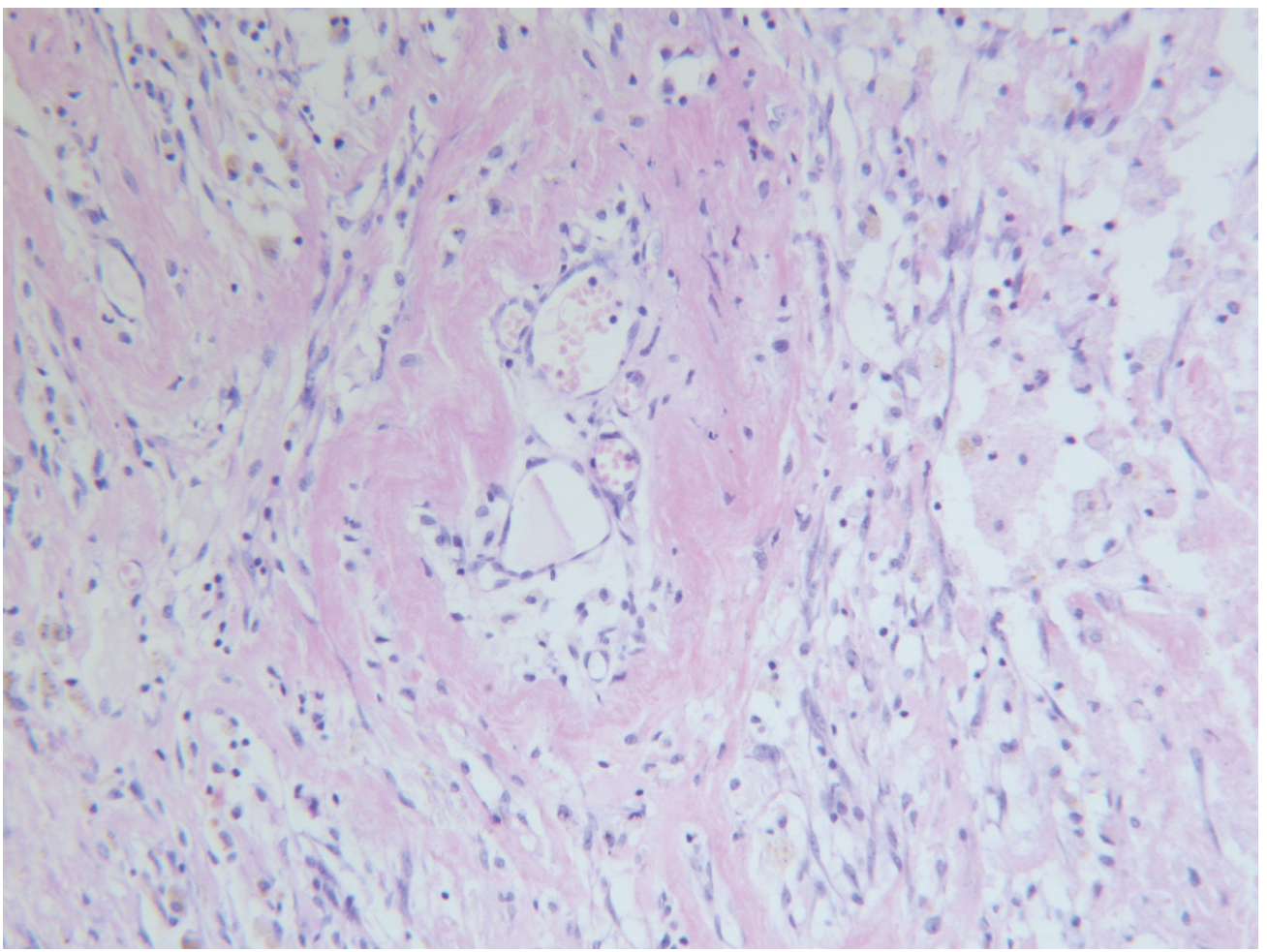

Figures 3a. Lung biopsy histological findings. Pulmonary infarction with pulmonary arterioles subocclusive and occlusive thrombosis. (H\&Ex20). Figure 3b. Near zone of infarction, occlusive thrombosis with recanalization (H\& Ex20). 


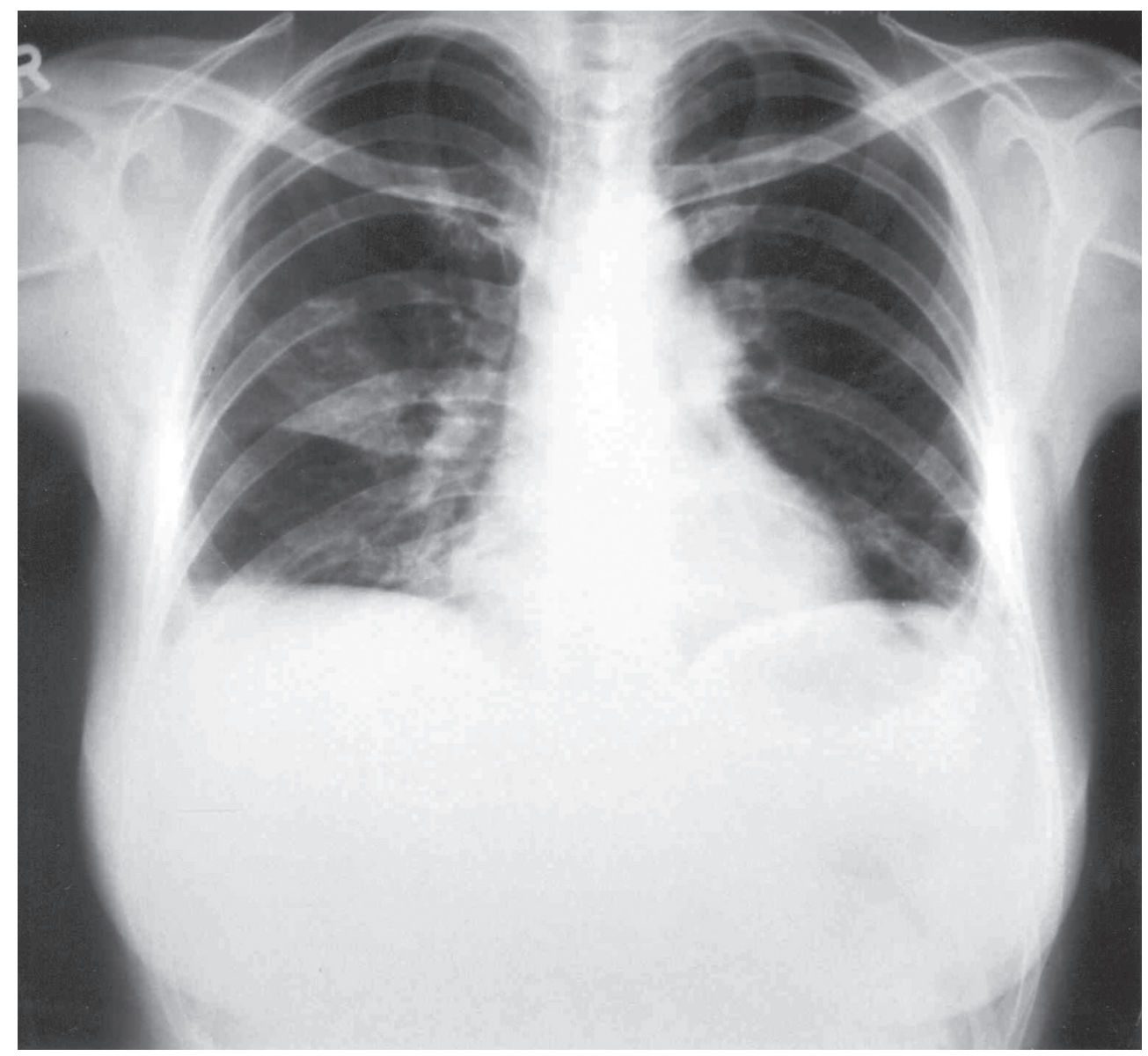

Figure 4. Standard postero-anterior chest radiograph of patient after lung biopsy. The appearance of new triangle shaped shadow in the right middle lung field.

products was at $72^{\circ} \mathrm{C}$ for $10 \mathrm{~min}$. The PCR reactions were performed in Mastercycler gradient apparatus (Eppendorf, Hamburg, Germany).

\section{DISCUSSION}

Our patient had bilateral subpleural nodules, normal D-dimer level and, thus, a low clinical probability of PTE that was estimated using the Geneva score [6]. Her PTE occurred shortly after open lung biopsy, most probably because of a combined effect of a congenitally hypercoagulable state, and the surgical procedure due to the presence of a heterozygous FII G20210A mutation.

The radiologic appearance of pulmonary infarction may vary depending on the underlying cause and the temporal evolution of the lesion [7]. Subpleural nodular opacities on chest radiography are atypical parenchymal infarctions, and surgical lung biopsy may sometimes be required to establish a correct diagnosis. Parambil et al. [3] reported that $65 \%$ of initially unrecognized pulmonary infarctions, which were later confirmed by histological examination, presented as solitary or multiple lung nodules on chest radiograph and/or CT.

In several studies, the negative predictive value of the combination of low clinical probability and normal D-dimer levels in exclusion of PTE approached $99.5 \%[8,9]$. For that reason, suspicion of PTE in our patient was initially abandoned and a lung biopsy was performed. A normal level of Ddimer, despite proven thromboembolic pulmonary infarctions on histologic examination, represented an intriguing issue. Normal D-dimer levels, when determined by the ELISA technique, have excellent negative predictive values of $91-98 \%$, and are considered adequate for exclusion of venous thromboembolism [10,11]. Similarly, normal D- 
dimer level determined by the latex agglutination method, has negative predictive value of about $88 \%$, and is not satisfactory for exclusion of recent PTE [12]. Although the rapid immunoturbidometric test that we used exhibited better sensitivity than the qualitative latex agglutination tests, its negative predictive value was lower than that of the ELISA method, which may be responsible for the negative results of D-dimer in our patient [12]. Furthermore, fibrin degradation products have a half-life of from 3-48 hours, and cause the D-dimer level to decrease over time [13]. Therefore, the long period between occurrence of symptoms and drawing of the blood sample may also be responsible for the normal Ddimer levels in our patient.

While the assays now available for D-dimer measurement have different sensitivities and specificities for the diagnosis of venous thromboembolism $[8,9,12]$, the D-dimer level is also affected by a patient's characteristics. For example, the value of D-dimer testing is significantly decreased if the renal function is affected, as study of patients with suspected pulmonary embolism and decreased glomerular filtration rate showed [14]. Gibson et al. [15] described cases when PTE was present in spite of a low D-dimer level, suggesting that patients with a likely clinical probability should undergo further diagnostic testing. The ventilation/ perfusion scintigraphy is non diagnostic in almost one-half to two-thirds of patients with a clinical suspicion of PTE [16], and its predictive value decreases if the clinical probability of PTE is low, as in our patient.

The relative risk of venous thromboembolic events is increased 2-4-fold in heterozygous carriers of the FII G20210A mutation when compared to non carriers [17]. The risk of venous thrombosis was significantly increased in patients with FII G20210A mutation in whom total hip arthroplasty was performed, compared to patients without this mutation [18]. Even a minor surgical procedure in patients with prothrombotic states may represent a risk factor for thrombosis [19].

\section{CONCLUSIONS}

The potential for thrombotic pulmonary infarction should be considered in patients with nodular lung infiltrates even when D-dimer values are nor- mal, and were determined by less sensitive methods or long after the occurrence of symptoms. Although venous thrombosis is a rare complication of open lung biopsies, testing for thrombophilic states in such patients may help the recognition of a hypercoagulable state and the implementation of appropriate antithrombotic prophylaxis after any surgical procedure is carried out.

\section{ACKNOWLEDGMENTS}

This study was supported by the Ministry of Science, Technology and Development of Serbia through contracts Nos. 143051/145061.

\section{REFERENCES}

1. Moser KM. Venous thromboembolism. Am Rev Respir Dis 1990; 141(1): 235-249.

2. Balakrishnan J, Meziane MA, Siegelman SS, Fishman EK. Pulmonary infarction: CT appearance with pathologic correlation. J Comput Assist Tomogr 1989; 13(6): 941-945.

3. Parambil JG, Savci D, Tazelaar H, Ryu J. Causes and presenting features of pulmonary infarctions in 43 cases identified by surgical lung biopsy. Chest 2005; 127(4): 1178-1183.

4. Wells PS. Integrated strategies for the diagnosis of venous thromboembolism. J Thromb Haemost 2007; 5(Suppl. 1): 41-50.

5. Poort SR, Rosendaal FR, Reitsma PH, Bertina RM. A common genetic variation in the 3'-untranslated region of the prothrombin gene is associated with elevated plasma prothrombin levels and an increase in venous thrombosis. Blood 1996; 88(10): 3698-3703.

6. Wicki J, Perneger TV, Junod AF, Bouneameaux H, Perrier A. Assessing clinical probability of pulmonary embolism in the emergency ward: a simple score. Arch Intern Med 2001; 161(1): 9297.

7. Greaves SM, Hart EM, Aberle DR. CT of pulmonary thromboembolism. Semin Ultrasound CT MR 1997; 18(5): 323-337.

8. Goekoop RJ, Steeghs N, Niessen RW, Jonkers GJ, Dik H, Castel A, Werker-van Gelder L, Vlasveld LT, van Klink RC, Planken EV, Huisman MV. Simple and safe exclusion of pulmonary embolism in outpatients using quantitative D-dimer 
and Well's simplified decision rule. Thromb Haemost 2007; 97(1): 146-150.

9. Kearon C, Ginsberg JS, Douketis J, Turpie AG, Bates SM, Lee AY, Crowther MA, Weitz JI, Brill-Edwards P, Wells P, Anderson DR, Kovacs MJ, Links LA, Julian JA, Bonilla LR, Gent M, Canadian Pulmonary Embolism Diagnosis Study(CANPEDS) Group. An evaluation of Ddimer in the diagnosis of pulmonary embolism: a randomized trial. Ann Intern Med 2006; 144(11): 812-821.

10. Perrier A, Desmarais S, Miron MJ, de Moerloose P, Lepage R, Slosman D, Didier D, Unqer PF, Patenaude JV, Bounameaux H. Non-invasive diagnosis of venous thrombomboembolism in outpatients. Lancet 1999; 353 (9148): 190-195.

11. Bounameaux $\mathrm{H}$, de Moerloose P, Perrier A, Miron MJ. D-dimer testing in suspected venous thromboembolism: an update. Q J Med 1997; 90(7): 437-442.

12. Oger E, Leroyer C, Bressollette L, Nonent M, Le Moigne E, Bizais Y, Amiral J, Grimaux M, Clavier J, Ill P, Abogral JF, Mottier D. Evaluation of a new, rapid, and quantitative D-dimer test in patients with suspected pulmonary embolism. Am J Respir Crit Care Med 1998; 158(1): 65-70.

13. Lip GY, Lowe GD. Fibrin D-dimer: a useful clinical marker of thrombogenesis? Clin Sci 1995; 89(3): 205-214.

14. Karami-Djurabi R, Klok FA, Kooiman J, Velthuis SI, Nijkeuter M, Huisman MV. D-dimer testing in patients with suspected pulmonary embolism and impaired renal function. Am J Med 2009; 122(11); 1050-1053.

15. Gibson NS, Sohne M, Gerdes VE, Nijkeuter M, Buller HR. The importance of clinical probability assessment in interpreting a normal D-dimer in patients with suspected pulmonary embolism. Chest 2008; 134(4): 789-793.

16. Verhaeghe R, Moerloose P, Greer I, Huisman MV, Hustinx R, Monreal M, Mortelmans L, Perrier A, Remy-Jardin M, Torbicki A, van Beek EJR, and other participants of the working group "Management of Pulmonary Embolism." Diagnostic aspects of pulmonary embolism. Eur Respir Mon 2004; 9(27): 15-24.

17. Ridker PM, Hennekens CH, Miletich JP. G20210A mutation in prothrombin gene and risk of myocardial infarction, stroke, and venous thrombosis in a large cohort of US men. Circulation 1999; 99(8): 999-1004.

18. Salvati EA, Della Valle AG, Westrich GH, Rana AJ, Specht L, Weksler BB, Wang P, Glueck CJ. The John Charnley Award: heritable thrombophilia and development of the thromboembolic disease after total hip arthroplasty. Clin Orthop Relat Res 2005; 441(8): 40-55.

19. Yamamoto T, Ito M, Nagata S, Suzuki H, Tagawa A, Nagase M, Hishida AJ. Catastrophic exacerbation of antiphospholipid syndrome after lung adenocarcinoma biopsy. J Rheumatol 2000; 27(8): 2035-2037. 